\title{
KUALITAS PELAYANAN IZIN MENDIRIKAN BANGUNAN RUMAH TINGGAL DI DINAS PENANAMAN MODAL DAN PELAYANAN TERPADU SATU PINTU KOTA DEPOK TAHUN 2016 - 2018
}

\author{
Ahmad Muksin dan Samsu Sadikin \\ Universitas Nasional Jakarta \\ Email: moechsienahmad@gmail.com dan samsusadikin23@gmail.com
}

\begin{abstract}
Abstrak
Penelitian ini dilatarbelakangi oleh rendahnya kualitas pelayanan IMB rumah tinggal di Dinas Penanaman Modal dan Pelayanan Terpadu Satu Pintu Kota Depok yang dinilai belum memuaskan masyarakat baik dari sarana dan prasarana pelayanan. Mengacu pada teori kualitas pelayanan digunakan sebagai indikator untuk menilai kualitas pelayanan, sedangkan metode penelitian yang digunakan adalah metode penelitian kualitatif melalui observasi dan wawancara kepada informan yang telah ditetapkan dalam penelitian ini. Hasil penelitian menunjukkan bahwa dimensi jaminan dan empati belum mendapatkan penilaian sangat baik dan belum memuaskan. Hal ini disebabkan karena adanya belum adanya kepastian waktu, biaya dan legalitas yang sesuai dengan ketentuan Peraturan Daerah dan Peraturan Walikota Depok. Sedangkan dimensi reliability (reliabilitas) mendapatkan penilaian yang cukup baik dari pemohon IMB rumah tinggal karena kemampuan petugas pelayanan dalam melakukan pemeriksaan berkas permohonan IMB rumah tinggal masih diperlukan peningkatan kemampuan dalam menggunakan peralatan komputerisasi. Oleh karena itu, pelayanan IMB rumah tinggal dapat dinilai berkualitas karena para pemohon IMB rumah tinggal dapat merasakan kepuasan terhadap pelayanan yang diberikan oleh petugas pelayanan di Kantor DPMPTSP Kota Depok.
\end{abstract}

Kata kunci: Pelayanan IMB, Kepuasan, Kualitas

\section{Pendahuluan}

Pemerintahan desa merupakan kegiatan pelayanan yang dilakukan oleh kepala desa dan perangkat desa yang bertujuan untuk mensejahterakan masyarakat di desa. Dengan demikian pemerintah desa merupakan ujung tombak dari pembangunan dimana pemerintah desa merupakan instansi pemerintahan yang terendah dan memiliki cakupan wilayah yang kecil sehingga diharapkan pemerintah desa dapat menyerap segala aspirasi dari masyarakat. Adanya penerapan ilmu administrasi pemerintahan desa diharapkan dapat mengoptimalkan kinerja seluruh aparat desa secara sempurna, sehingga dapat memberikan pelayanan prima dan maksimalnya pembangunan bagi masyarakat.

Salah satu Program Pemerintah untuk menjaga ketertiban dalam perizinan mendirikan bangunan, Pemerintah Kota Depok telah mengeluarkan Peraturan Daerah 
Kota Depok Nomor 2 Tahun 2016 tentang Perubahan Atas Peraturan Daerah Kota Depok Nomor 13 Tahun 2013 tentang Bangunan dan Izin Mendirikan Bangunan sebagai regulasi yang diimplementasikan oleh Pemerintah Kota Depok melalui Dinas Penanaman Modal dan Pelayanan Terpatu Satu Pintu (DPMPTSP) Kota Depok dalam memberikan pelayanan hingga penerbitan Izin Mendirikan Bangunan (IMB), khusunya IMB Rumah Tinggal bagi masyarakat di Kota Depok.

Berdasarkan data yang penulis peroleh dari Dinas Penanaman Modal dan Pelayanan Terpadu Satu Pintu (DPMPTSP) Kota Depok maka dapat diketahui jumlah permohonan IMB Rumah Tinggal tahun 2016 - 2018, seperti dapat dilihat pada tabel berikut ini

Tabel 1

Jumlah Pemohon IMB Rumah Tinggl di Dinas Penanaman Modal dan PTSP Kota Depok Provinsi Jawa Barat Tahun 2016 - 2018

\begin{tabular}{|c|c|c|c|c|c|}
\hline \multirow[t]{2}{*}{ Tahun } & \multirow{2}{*}{$\begin{array}{c}\text { Jumlah } \\
\text { Pemohon } \\
\text { IMB } \\
\text { Rumh } \\
\text { Tinggal }\end{array}$} & \multicolumn{2}{|c|}{$\begin{array}{c}\text { Jumlah IMB } \\
\text { Rumah Tinggal yang } \\
\text { Terbit }\end{array}$} & \multirow{2}{*}{$\begin{array}{c}\text { Jumlah } \\
\text { IMB } \\
\text { Rumah } \\
\text { Tinggal } \\
\text { dalam } \\
\text { Proses }\end{array}$} & \multirow{2}{*}{$\begin{array}{c}\text { Jumlah } \\
\text { IMB } \\
\text { Rumah } \\
\text { Tinggal } \\
\text { yang } \\
\text { Ditolak }\end{array}$} \\
\hline & & $\begin{array}{c}\text { IMB } \\
\text { Rumah } \\
\text { Tingal yang } \\
\text { terbit }\end{array}$ & $\begin{array}{c}\text { IMB } \\
\text { Rumah } \\
\text { tinggal yang } \\
\text { belum terbit }\end{array}$ & & \\
\hline 2016 & 3.107 & 2.943 & 164 & 124 & 40 \\
\hline 2017 & 3.375 & 2.999 & 376 & 322 & 54 \\
\hline 2018 & 3.472 & 3.372 & 100 & 10 & 90 \\
\hline
\end{tabular}

Sumber: Dinas Penanaman Modal dan Pelayanan Terpadu Satu Pintu Kota Depok Tahun 2018.

Berdasarkan Laporan Akuntabilitas Kinterja Instansi Pemerintah (LAKIP) DPMPTSP Kota Depok Tahun 2017 dapat diketahui kendala yang dihadapi dalam penyelenggaraan pelayanan perizinan khususnya IMB rumah tinggal yaitu masih terbatasnya sarana dan prasarana untuk mendukung pelayanan perizinan, belum maksimalnya pelayanan berbasis online, dan belum optimalnya kualitas pelayanan perizinan sehingga perizinan dalam penerbitan Izin Mendirikan Bangunan rumah tinggal (IMB Rumah Tinggal) masih berlangsung lama.

Pelayanan Izin Mendirikan Bangunan, khususnya IMB Rumah Tinggal merupakan jenis pelayanan umum yang disediakan oleh Dinas Penanaman Modal dan Pelayanan Terpadu Satu Pintu (DPMPTSP) di Kota Depok. Dilihat dari segi organisasi dapat dinilai dari kualitas pelayanan yang diberikan, dari perkembangan di wilayah Kota Depok yang semakin meningkat jumlah pertumbuhan penduduknya dan runah tumbuh atau rumah tinggal yang bertambah sehingga semakin meningkatnya kebutuhan akan pembangunan fisik di wilayah tersebut membuat masyarakat memiliki kewajiban untuk memiliki IMB agar bangunan itu diakui oleh pemerintah.

Konsep kualitas Dalam ISO 8420 (Quality Vocabulary) dalam (Gaspersz, 2003) mendefinisikan kualitas sebagai totalitas dari karakteristik suatu produk yang menunjang kemampuannya untuk memuaskan pelanggan (customer satisfaction) atau konformansi terhadap kebutuhan atau persyaratan (conformance to the requirement). 
Menurut Kotler dalam (Ridwan, 2007) mengemukakan bahwa: Pelayanan adalah setiap kegiatan yang menguntungkan dalam suatu kumpulan atau kesatuan, dan menawarkan kepuasan meskipun hasilnya tidak terikat pada suatu produk secara fisik".

Selanjutnya kualitas pelayanan penilai pelayanan publik itu sendiri, terdapat sejumlah dimensi kualitas yang dapat digunakan. Misalnya saja apabila kita meminjam pendapat (Parasuraman, A., Zeithaml, V. A., 1985) mengunakan dimensi ukuran kualitas, yaitu: a) Tangible, yaitu fasilitas fisik, peralatan, pegawai dan fasilitasfasilitas komunikasi yang dimiliki oleh penyedia layanan; b) Reliability atau realibilitas adalah kemampuan untuk menyelengarakan pelayanan yang dijanjikan secara akurat; c) Responsiveness atau responsivitas adalah kerelaan untuk menolong pengguna layanan dan menyelenggarakan pelayanan secara ikhlas; d) Assurance atau kepastian adalah pengetahuan, kesopanan dan kemampuan para petugas penyedia layanan dalam memberikan kepercayaan kepada pengguna layanan; dan e) Empathy adalah kemampuan memberikan perhatian kepada pengguna layanan secara individual.

Konsep perizinan menurut Manan dalam (Ridwan, 2007) menyebutkan bahwa izin dalam arti luas berarti persetujuan dari penguasa berdasarkan perundang-undangan untuk memperbolehkan tindakan atau perbuatan yang secara umum dilarang, sehingga izin merupakan suatu tindakan hukum yang sah dan diatur oleh perundang-undangan yang telah di tentukan. Sedangkan (Spelt et al., 1993) menyatakan bahwa: "Izin adalah suatu persetujuan dari penguasa berdasarkan undang undang atas peraturan pemerintah untuk dalam keadaan tertentu menyimpang dari ketentuan menyimpang dari ketentuan ketentuan larangan perundangan. Dengan demikian dalam melakukan pembangunan bangunan baru, mengubah, memperluas atau mengurangi bangunan diperlukan izin dalam pelaksanaan kegiatan tersebut.

Pelayanan IMB khususnya IMB rumah tinggal Kota Depok, fenomena permasalahan tentang IMB Rumah Tinggal dalam hal ini penyelenggaraan perizinan IMB Rumah Tinggal masih terbatas sarana dan prasarana untuk mendukung pelayanan perizinan, dan juga belum maksimalnya pelayanan berbasis online, serta kurang memuaskan dan kurang kecermatan pelayan atau petugas dalam melakukan pemeriksaan dan kemampuan menggunakan sistem komputerisasi sehingga proses pengajuan IMB Rumah Tinggal dapat dinilai lambat.

\section{Metode Penelitian}

Merujuk pada permasalahan yang telah dirumuskan maka jenis penelitian yang digunakan adalah deskriptif kualitatif yang mengambil lokasi di Dinas Penanaman Modal dan Pelayanan Terpadu Satu Pintu Kota Depok. Teknik pengambilan sampel dalam penelitian ini adalah purposive sampling dan acidental sampling dengan sumber data ialah data primer dan sekunder. Data primer disini diperoleh dari pegawai DPMPTSP Kota Depok dan masyarakat yang sedang mengurus, sedangkan data sekunder yang digunakan adalah berupa dokumen dan arsip serta perundang-undangan yang bersangkutan dengan penerbitan IMB. Adapun teknik pengumpulan data yang digunakan yaitu wawancara, sokumentasi dan observasi lapangan. Validitas data yang 
digunakan adalah triangulasi metodelogi dengan teknik analisis interaktif yang mempunyai 3 (tiga) kompenen yakni reduksi data, penyajian data dan penarikan kesimpulan (Sugiyono, 2014).

\section{Hasil dan Pembahasan}

Berdasarkan hasil analisis dan pembahasan dalam skripsi ini, penulis dapat menyimpulkan bahwa pelayanan IMB rumah tinggal di Kantor DPMPTSP Kota Depok dapat menunjukkan kualitas pelayanannya ditunjukkan pada interaksi antara petugas pelayanan dengan pemohon IMB rumah tinggal melalui lima dimensi kualitas pelayanan Parasuraman sebagai berikut:

Dimensi Tangibles (Berwujud Fisik) pada penyelenggaraan kualitas pelayanan IMB rumah tinggal yaitu: fasilitas fisik, peralatan, sarana ruang tunggu, dan fasilitasfasilitas komunikasi lainnya cukup representatif namun perlu diperhatikan penyejuk ruangan, ventilasi dan running text yang terpasang dalam koridor pintu masuk. Kualitas pelayanan di terapkan oleh DPMPTSP Kota Depok sebagai wujud pelayanan prima dalam penerbitan IMB setelah pemohon izin melengkapi persyaratan yang ditentukan telah menjadi keputusan. Dalam memberikan pelayanan tentunya terdapat masalahmasalah yang muncul dalam prosesnya. Keluhan dalam penanganan informasi masih sulit dijalankan akibat birokrasi yang rumit serta kurangnya keramahan dalam pelayanan yang diberikan apabila berkaitan dengan instansi pemerintahan. Sudah tidak asing lagi bahwa masyarakat sering kesulitan dalam mendapatkan pelayanan yang baik dari instansi pemerintah.

Dimensi Reliability (Reliabilitas) pada Penyelenggaraan Kualitas Pelayanan IMB Rumah Tinggal di Kantor DPMPTSP Kota Depok. Berdasarakan hasil penelitian yang dilakukan DPMPTSP Kota Depok memiliki prosedur yang mudah dalam pelaksanaan penerbitan IMB bagi masyarakat, prosedur tersebut menjadi acuan untuk memberikan pelayanan yang sebaik-baiknya kepada masyarakat. Namun masih ada untuk pengurusan izin yang paket waktunya 15 hari, namun dalam prakteknya masih ada yang diselesaikan dalam waktu 1 bulan, sehingga tidak sesuai dengan SOP dari DPMPTSP Kota Depok.

Dimensi Responsiveness (Daya Tanggap) pada Penyelenggaraan Kualitas Pelayanan IMB Rumah Tinggal di Kantor DPMPTSP Kota Depok. Berdasarkan hasil penelitian yang dilakukan sudah berusaha dengan menyeleksi para petugas yang diperkerjakan disini, selain itu pemberian uraian kerja kepada setiap petugas layanan dalam memberikan pelayanan cukup baik dalam melakukan pelayanan sehingga pelayanan yang dilakukan dapat dilaksanakan secara cepat. Selanjutnya pemberian infromasi dengan jelas kepada masyarakat juga merupakan bentuk komitmen organisasi (Avianto, 2018) dalam aspek responsiveness yang dilakukan oleh DPMPTSP Kota Depok.

Dimensi Assurances (Jaminan) pada Penyelenggaraan Kualitas Pelayanan IMB Rumah Tinggal di Kantor DPMPTSP Kota Depok. Aspek ini dilihat adanya pelayanan perizinan mendirikan bangunan di Kota Depok sendiri di urus oleh Dinas Penanaman 
Modal dan Pelayanan Terpadu Satu pintu Kota Depok dengan sistem One Stop Service dalam mengurus perizinan IMB dimulai dari pemohon memberikan persyatan sampai penerbitan SK IMB dilakukan disini. Sehingga aspek assurance yang terdapat DPMPTSP Kota Depok dalam memberikan pelayanan penerbitan IMB sudah terdapat jaminan yang diberikan. Adanya pemberian jaminan biaya pelayanan yang di bebankan sudah terperinci dengan jelas melalui Surat Ketetapan Retribusi Daerah (SKRD) serta tidak terdapatnya biaya tambahan diluar rincian biaya yang dijelaskan melalui SKRD merupakan bentuk sikap petugas DPMPTSP untuk menumbukan rasa percaya terhadap masyarakat selaku penerima pelayanan

Dimensi Empathy (Empati) pada Penyelenggaraan Kualitas Pelayanan IMB Rumah Tinggal di Kantor DPMPTSP Kota Depok, mengengai empati yang diberikan oleh petugas DPMPTSP dalam memberikan pelayanan kepada masyarakat selaku pemohon izin melalui bentuk perhatian pribadi yang diberikan oleh petugas dalam memberikan kemudahan petugas dihubungi yaitu dengan memberikan nomor telfon kantor apabila masyarakat mendapat permasalahan mengenai persyaratan yang belum dipahami atau membutuhkan informasi tambahan. Selain itu dengan adanya usaha pemberian pelatihan kepribadian yang dilakukan DPMPTSP terhadap petugasnya masyarakat sebagai penerima pelayanan sudah merasakan dampak akan pelatihan kepribadian yang dilakukan oleh DPMPTSP Kota Depok.

Dari kelima dimensi kualitas pelayanan tersebut di atas dapat ditemukan bahwa dimensi assurances (jaminan) menempati dimensi yang dinilai sangat baik oleh pemohon IMB rumah tinggal karena adanya kepastian biaya dan waktu serta legalitas yang sesuai dengan peraturan perundang-undangan, sedangkan dimensi reliability (reliabilitas) menempati dimensi yang dinilai kurang baik oleh pemohon IMB rumah tinggal karena kecermatan dalam pemeriksaan berkas permohonan IMB rumah tinggal dengan kemampuannya menggunakan peralatan komputerisasi.

Faktor Penghambat Proses Pelayanan Perizinan IMB di DPMPTSP Kota Depok memang secara keseluruhan, dari semua dimensi yang ada memiliki kualitas pelayanan yang bisa dikatakan baik. Tetapi tetap ada dimensi kualitas yang masih harus ditingkatkan, karena dari hasil observasi yang dilakukan masih ada beberapa pihak yang belum diberikan keterangan mengenai dimensi-dimensi yang dianggap kurang ini. Dimensi tersebut antara lain: tangibles, reliability, kejelasan dan kepastian tentang tata cara, keterbukaan, efisiensi, ekonomis, dan ketepatan waktu.

Faktor Penghambat Pelayanan Perizinan IMB Bagi Pihak DPMPTSP Kota Depok, antara lain: a) Ada keberatan atas besaran retribusi; b) Peruntukan perizinan yang tidak sesuai dengan izin bangunan yang dikeluarkan DPMPTSP Kota Depok; dan c) Kesadaran masyarakat akan pentingnya IMB masih kurang. Faktor Penghambat Pelayanan Perizinan IMB Bagi Pihak Masyarakat antara lain: 1) DPMPTSP Kota Depok berpusat di kota sehingga kesulitan dijangkau masyarakat yang domisilinya jauh dari pusat Kota Depok; 2) Belum adanya sosialisasi pelayanan berbasis on-lineintegrated yang dapat langsung digunakan dan diinput; 3) Masih adanya keberatan dengan nominal retribusi IMB di DPMPTSP Kota Depok; 
Selain faktor penghambat, peneliti menemukan adanya faktor pendukung Pelayanan Perizinan IMB DPMPTSP Kota Depok berdasarkan hasil pembahasan wawancara yang dilakukan. Hasilnya menunjukkan bahwa faktor-faktor yang dapat dijadikan pendukung untuk proses pelayanan perizinan di DPMPTSP Kota Depok diantaranya: 1) Dilihat dari faktor kulitas pelayanan yang digunakan, dimensi yang memiliki kategori baik atau sudah memenuhi kriteria dimensi kualitas pelayanan, bisa menjadi faktor pendukung pelayanan perizinan. Dimensi kualitas yang dimaksud antara lain: responsiveness, empathy, dan reliability; 2) Adanya ksesuaian antara visi dan misi yang dimiliki DPMPTSP Kota Depok untuk menciptakan kualitas pelayanan perizinan; 3) Adanya perda retribusi yang mengatur regulasi besaran biaya IMB; dan 4) Komitmen DPMPTSP Kota Depok terus memberikan pelayanan yang mudah, cepat dan tepat dan selalu terjaga dengan baik.

\section{Kesimpulan}

Kualitas pelayanan administrasi perizinan penerbitan izin mendirikan bangunan di Dinas Penanaman Modal dan Pelayanan Terpadu Satu Pintu Kota Depok. Berdasarakan Indikator service quality (Parasuraman, A., Zeithaml, V. A., 1985) yaitu tangibles, reliability, responsiveness, assurance dan emphaty secara keseluruhan sudah dilaksanakan, akan tetapi belum optimal. Menunjuk dari hasil pengamatan dan pembahasan diatas dapat beberapakesimpulan sebagai berikut :

1. Dimensi tangibles (Bukti Fisik/Berwujud) dinilai kualitas pelayanannya oleh pemohon IMB rumah tinggal dengan penilaiannya yang baik dan memuaskan karena pemohon IMB dapat merasakan kenyamanan tempat pelayanan serta petugas pelayanan yang memiliki kedisiplinan dalam memberikan pelayanan sehingga dapat memudahkan proses dan akses layanan dengan menggunakan alat bantu berupa sistem komputerisasi yang terhubung secara online.

2. Dimensi reliability (reliabilitas/kepercayaan) dinilai kualitas pelayanannya oleh pemohon IMB rumah tinggal dengan penilaiannya yang kurang baik dan kurang memuaskan bagi pemohon karena kurangnya kecermatan petugas dalam melakukan pemeriksaan dengan kemampuannya menggunakan sistem komputerisasi sehingga proses pengajuan IMB rumah tinggal dapat dinilai agak lamban dan kurang baik.

3. Dimensi responsiveness (daya tanggap) dinilai kualitas pelayanannya oleh pemohon dengan penilaian yang baik dan memuaskan karena dapat merespon dengan cepat, tepat dan cermat dari keluhan yang diajukan oleh pemohon.

4. Dimensi assurances (jaminan) dinilai kualitas pelayanannya dengan penilaian yang sangat baik karena pelayanan IMB rumah tinggal telah memiliki kepastian biaya dan waktu serta legalitas sebagaimana telah diatur dalam peraturan daerah maupun peraturan walikota Depok terkait dengan pengurusan IMB serta retribusi izin bangunan.

5. Dimensi empathy (empati) dinilai kualitas pelayanannya dengan penilaian yang baik karena petugas pelayanan dapat memberikan pelayanan dengan sikap yang ramah, sopan santun dan tidak membeda-bedakan pemohon dalam menanggapi 
Kualitas Pelayanan Izin Mendirikan Bangunan Rumah Tinggal

setiap keluhan yang diajukan oleh pemohon IMB rumah tinggal di Kantor DPMPTSP Kota Depok. 


\section{BIBLIOGRAFI}

Avianto, B. N. (2018). Analisis Indeks Kepuasan Pelayanan Administratif Disdukcapil Kabupaten Brebes Dalam Presfektif Loyalitas Publik. Syntax Literate; Jurnal Ilmiah Indonesia, 3(7), 25-44.

Gaspersz, V. (2003). Manajemen Bisnis Total-Total Quality Management. Penerbit PT. Gramedia Pustaka Utama, Jakarta.

Parasuraman, A., Zeithaml, V. A., dan L. L. B. (1985). A Conceptual Model of Service Quality and Its Implication for Future Research. Journal of Marketing.

Ridwan, H. (2007). Hukum Administrasi Negara. PT. Raja Grafindo Persada.

Spelt, N. M., Ten Berge, J., \& Hadjon, P. M. (1993). Pengantar hukum perizinan. Yuridika.

Sugiyono. (2014). Metode Penelitian Manajemen. Alfabeta. 